REVISTA ECONOMÍA

Vol. 67, N. ${ }^{\circ}$ Io6 (noviembre 20I5), II-35

\title{
POLÍTICAS PÚBLICAS Y EMPLEO \\ INFORMAL EN ECUADOR: 2007-2015
}

\author{
MAURICIO LEÓN \\ Universidad Central del Ecuador \\ Recepción manuscrito: 4 de agosto de 2015 \\ Aceptación versión final: 30 de octubre de 2015
}

\begin{abstract}
RESUMEN Este análisis identifica la relación entre las políticas públicas laborales y de seguridad social implementadas en el Ecuador entre 2007 y 2015 y la reducción observada en el empleo informal. La evidencia sugiere que influyó una política activa para hacer cumplir a los empleadores con sus obligaciones laborales: cambios legales que fortalecieron los derechos de los trabajadores; penalización de la no afiliación a la seguridad social; sistema de planificación que orientó las políticas hacia el aumento de la cobertura de la seguridad social; reactivación de las inspectorías del trabajo; y reformas administrativas del Instituto Ecuatoriano de Seguridad Social.
\end{abstract}

PALABRAS CLAVE Empleo informal, política pública, laboral, seguridad social.

\begin{abstract}
This analysis identifies the relationship between the public working policies and the ones about social security which have been implemented in Ecuador between 2007 and 2015, as well as the reduction observed in informal work. The evidence suggests that it was an active policy which influenced employers on making them comply with their labor duties. These legal changes strengthened workers' rights and penalized the lack of affiliation of the workers to the social security. This planning system also oriented policies towards the increase of the social security coverage, reactivated work inspections, and permitted management reforms in the Instituto Ecuatoriano de Seguridad Social (Social Security System of Ecuador).
\end{abstract}

KEYWORDS Informal work, public labor policy, social security.

JEL CODES E26, H55, Jo8, J46, J48, J81, J88.

\section{INTRODUCCIÓN}

El objetivo de este análisis ${ }^{1}$ es comprender la relación entre las políticas públicas laborales y de seguridad social del gobierno de Rafael Correa y la reducción del empleo informal en el Ecuador en el período 2007-2015. Para ello se presentan estadísticas descriptivas de la evolución del empleo informal y el sector informal, se detallan las principales políticas laborales y de seguridad social implementadas y se revisan los resultados relevantes de la literatura empírica reciente sobre la informalidad en el Ecuador. En particular se busca identificar las 
reformas legales e institucionales que pueden haber contribuido a la reducción del empleo informal, mediante la revisión de las normas publicadas en el Registro Oficial, los informes de rendición de cuentas ministeriales y los documentos de planificación del gobierno. Por lo tanto, no se trata de un análisis exhaustivo de toda la política laboral y del trabajo. Tampoco se pretende explicar o demostrar las relaciones causales entre políticas y empleo informal ya que ello requeriría de evaluaciones de impacto rigurosas, experimentales o cuasiexperimentales, que aíslen los efectos de cada una de las políticas indagadas de otros factores determinantes posibles, las cuales están fuera del alcance de este estudio. ${ }^{2}$

El marco conceptual corresponde a las definiciones de informalidad establecidas por la Organización Internacional del Trabajo. Para esta institución, la economía informal comprende tanto el sector informal como el empleo informal. En la Decimoséptima Conferencia Internacional de Estadísticos del Trabajo de la orT se adoptó una definición de empleo informal que hace referencia a las características del puesto, empleo o trabajo (OIT, 2003, pp. 51-58), en contraste con la definición de sector informal establecida en la Decimoquinta Conferencia Internacional de Estadísticos del Trabajo y referida a las características del establecimiento o unidad productiva (OIT, 1993, pp. 1-16).

En el país, desde 2007, la nueva definición estadística del sector informal elaborada por el Instituto Nacional de Estadística y Censos, inec, comprendía los trabajadores que se encuentran en establecimientos de 10 trabajadores o menos y no tienen Registro Único de Contribuyentes (RUC), o no llevan contabilidad, o no tienen cuadernos de cuentas. En 2015 se ajustó la definición únicamente a la no tenencia de RUC. ${ }^{3}$ Es decir, comprende tanto los establecimientos de empleadores informales como los establecimientos informales de trabajadores por cuenta propia. El empleo informal, por su parte, abarca los patronos y trabajadores por cuenta propia del sector informal, los trabajadores no remunerados, y los asalariados y trabajadores domésticos que no reciben de su empleador seguridad social o seguro médico. En consecuencia, se puede tener empleo informal tanto en el sector formal como en el sector informal y el servicio doméstico. Entonces, se esperaría que las políticas públicas dirigidas a ampliar la cobertura de la seguridad social reduzcan el empleo informal y son éstas las que se enfatizan en este estudio.

Los datos al 2015 evidencian la gran dimensión de la informalidad en el mercado laboral ecuatoriano: cerca de seis de cada diez ocupados son empleados informales y cuatro de cada diez están empleados en el sector informal. ${ }^{4}$ Se observa también que entre 2007 y 2015 disminuyó tanto la tasa de empleo informal como la tasa del sector informal (ver Figura 1). ${ }^{5}$ En efecto, el empleo informal a nivel nacional cayó de $74,1 \%$ a $57,3 \%$. La tasa de empleados informales del sector formal, como porcentaje del total de ocupados, pasó de 16,3\% a 10,2\%. También se redujo la tasa de empleo informal del servicio doméstico de 2,9\% a 1,5\%. El empleo informal del sector informal disminuyó de 44,9\% a 40,1\% (ver Tabla 1). Por otra parte, la fuerza laboral nacional afiliada o cubierta por la seguridad social se incrementó de $26,3 \%$ a 44,2\% entre 2007 y 2015 (ver Figura 2). En particular, el porcentaje de la fuerza laboral urbana con seguridad social subió de $29,2 \%$ a 47,1\% entre 2007 y 2015.

El sector informal a nivel nacional pasó de 45,1\% a 40,4\% entre 2007 y 2015 (ver Figura 1). En contraposición, el aumento de los trabajadores por cuenta propia ha presionado al alza el sector informal: pasaron de representar el 29,8\% de los ocupados en 2007 a significar el 31,2\% 
Figura 1. Ocupados en empleos informales y ocupados en el sector informal

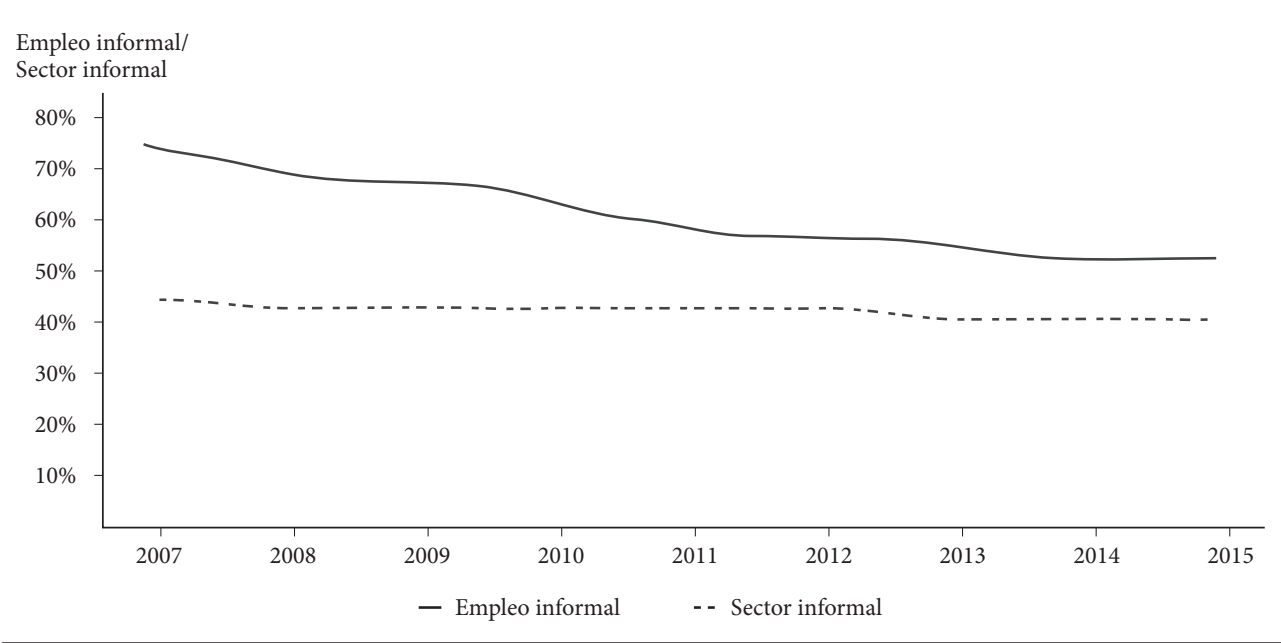

Fuente: INEC, Encuestas de empleo, subempleo y desempleo de varios años.

Figura 2. PEA afiliada o cubierta por la seguridad social

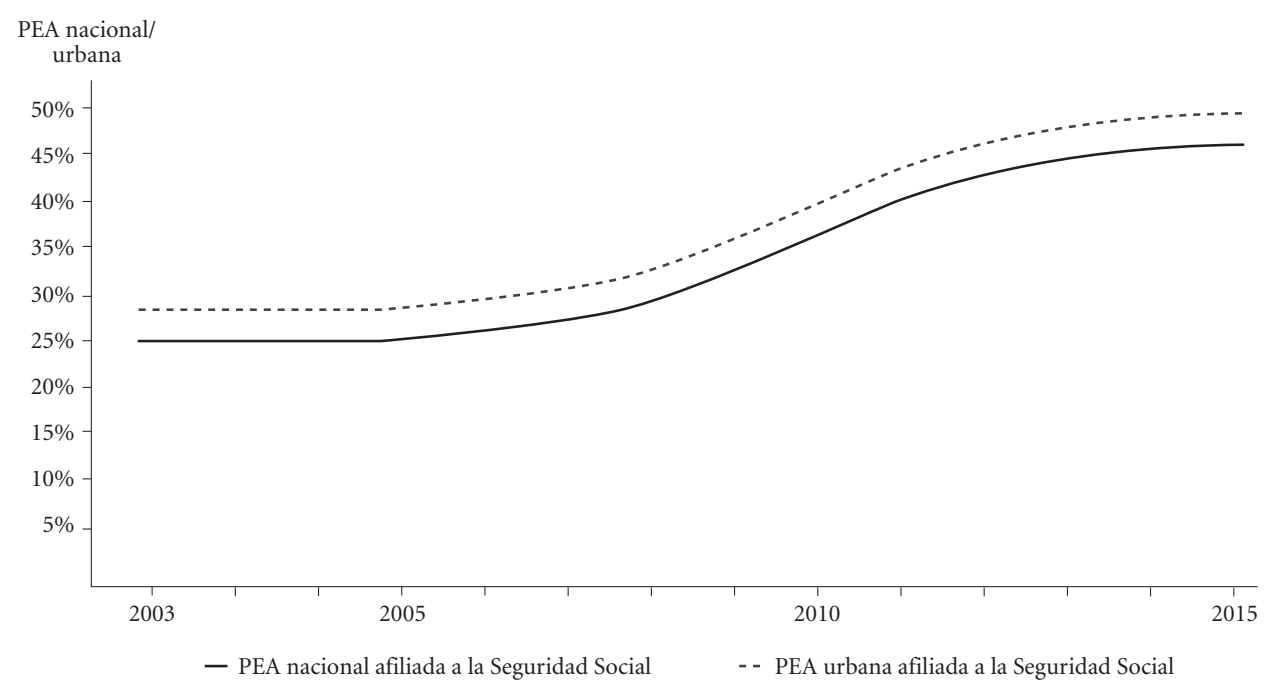

Fuente: INEC, Encuestas de empleo, subempleo y desempleo de varios años.

en 2015. Este incremento del trabajo por cuenta propia se explicaría parcialmente por la dificultad que enfrentan los emprendimientos de baja productividad para absorber los mayores costos que implica afiliar a los trabajadores a la seguridad social, pagar el salario mínimo y cumplir con los impuestos. 
En resumen, el empleo informal disminuyó, hecho que se pretende comprender en el resto del artículo que contiene un análisis breve del comportamiento de la economía y la evolución del empleo informal, una descripción de las principales políticas públicas laborales y de seguridad social implementadas entre 2007 y 2015 y que tienen relación con la disminución del empleo informal, y una sección de conclusiones.

\section{CRECIMIENTO ECONÓMICO, AUMENTO DEL GASTO SOCIAL E INCREMENTO DEL EMPLEO ASALARIADO}

Entre 2000 y 2014, ayudada por el incremento del precio del petróleo, la economía ecuatoriana creció en promedio a una tasa anual de 4,3\%, que en términos per cápita representa una tasa promedio anual de 2,4\%. La economía no petrolera creció a una tasa anual de 4,9\%. En el período 2007-2014, a pesar el impacto negativo de la crisis económica y financiera mundial, la economía creció en promedio a una tasa anual de 4,3\%, mientras que la economía no petrolera lo hizo a una tasa anual de 5,1\%. Desde el segundo semestre de 2014, debido a la caída del precio del petróleo, la economía sufrió una fuerte desaceleración y se ha estancado. La proyección oficial de crecimiento para el 2015, elaborada por el Banco Central del Ecuador, es de 0,4\%, mientras estimaciones del Fondo Monetario Internacional señalan una tasa negativa de -0,6\%.

En este último período se produjo un aumento importante del gasto social en particular y del gasto público en general. Efectivamente, el gasto en educación y salud pasó de 3,9\% del PIB en 2007 a 5,7\% del PIB en 2014 y el gasto público total del gobierno central subió de 16,0\% del PIB a 26,0\% del PIB. Este aumento del gasto público y social estuvo aparejado de un incremento de los asalariados gubernamentales, que en su mayoría corresponden a empleos formales con afiliación a la seguridad social. A nivel nacional, los asalariados de gobierno se incrementaron de 7,6\% del total de ocupados en 2007 a 9,7\% en 2015. En términos absolutos, según las encuestas de empleo, aumentaron de 460 mil a 689 mil (ver Tabla 2). Concordantemente, el consumo del gobierno general aumentó de 10,9\% del PIB real en 2007 a 13,9\% en 2014.

Entre esos años se observa también un incremento de los asalariados privados de $29,7 \%$ a $32,8 \%$ y una disminución de los empleados tercerizados (de 1,1\% a o,1\%) y los trabajadores auxiliares no remunerados (de 10,4\% a 8,9\%). Las empleadas domésticas disminuyeron entre 2007 y 2015 (de 3,3\% a 2,7\%). La reducción de las empleadas domésticas tuvo su correlato en la disminución del valor agregado bruto del servicio doméstico, que presentó tasas de crecimiento negativas en 2011 y 2012 (de -3,5\% y -1,4\%, respectivamente), recuperándose en 2013 a una tasa de $1,8 \%$ y en 2014 a 4,8\%. Se observa, en general, cierto cambio en la estructura del mercado laboral urbano y una reducción del empleo informal en todas las categorías de trabajo (ver Tabla 3). Los cuentapropistas aumentaron tanto en términos absolutos (en 439.00o personas) como en su participación en el total de ocupados. Los patronos disminuyeron en 72. ooo personas (ver Tabla 2).

Si bien el crecimiento económico de los períodos 2000-2006 y 2007-2014 son similares, se observa un punto de quiebre en la tendencia de la fuerza laboral afiliada a la seguridad social a partir de 2007 (ver Figura 2), lo que sugiere que su aumento podría estar relacionado con modificaciones en las políticas públicas antes que con el crecimiento económico. Se requiere 
Tabla 1. Empleo informal y formal en la ocupación total (\%)

\begin{tabular}{lrrrrrrrrr}
\hline SECTORES & 2007 & \multicolumn{1}{c}{2008} & \multicolumn{1}{c}{2009} & 2010 & 2011 & 2012 & 2013 & 2014 & 2015 \\
\hline Empleo informal & 74,1 & 71,6 & 69,9 & 66,0 & 62,2 & 60,4 & 58,8 & 57,1 & 57,3 \\
Sector formal & 16,3 & 16,9 & 15,0 & 14,7 & 10,9 & 11,1 & 10,7 & 10,8 & 10,2 \\
Sector informal & 44,9 & 43,2 & 43,6 & 42,5 & 42,3 & 40,5 & 39,7 & 39,3 & 40,1 \\
Servicio doméstico & 2,9 & 3,1 & 2,9 & 2,3 & 1,6 & 1,8 & 2,1 & 1,8 & 1,5 \\
No clasificado & 9,9 & 8,4 & 8,5 & 6,4 & 7,4 & 7,0 & 6,4 & 5,2 & 5,6 \\
Empleo formal & 25,9 & 28,4 & 30,1 & 34,0 & 37,8 & 39,6 & 41,2 & 42,9 & 42,7 \\
Sector formal & 24,7 & 27,0 & 28,7 & 32,5 & 35,6 & 37,6 & 38,7 & 40,1 & 40,3 \\
Sector informal & 0,2 & 0,2 & 0,2 & 0,3 & 0,4 & 0,3 & 0,4 & 0,4 & 0,3 \\
Servicio domestico & 0,4 & 0,4 & 0,5 & 0,6 & 0,7 & 0,7 & 1,0 & 1,4 & 1,2 \\
No clasificado & 0,7 & 0,8 & 0,7 & 0,6 & 1,0 & 1,0 & 1,1 & 1,0 & 0,9 \\
\hline
\end{tabular}

Fuente: INEC, Encuestas de empleo, subempleo y desempleo de varios años.

Tabla 2. Empleo informal y formal (miles de personas)

\begin{tabular}{|c|c|c|c|c|c|c|c|c|c|c|}
\hline AÑO & 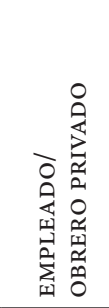 & 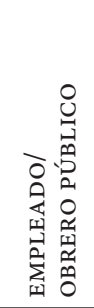 & 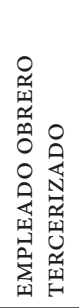 & 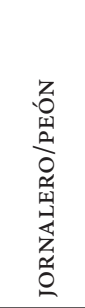 & 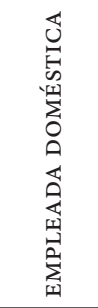 & $\begin{array}{l}0 \\
z \\
0 \\
\approx \\
\text { 崩 }\end{array}$ & 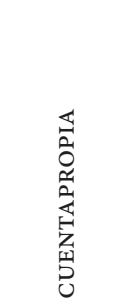 & 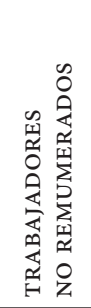 & 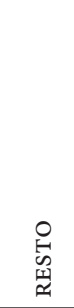 & 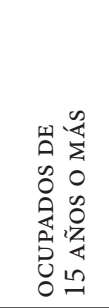 \\
\hline 2007 & $1.786,5$ & 460,2 & 66,8 & 742,4 & 200,7 & 313,3 & $1.791,5$ & 627,1 & 30,9 & $6.019,3$ \\
\hline 2008 & $1.808, \mathrm{o}$ & 492,4 & 15,8 & 823,7 & 207,5 & 317,9 & $1.746,2$ & 573,6 & 20,3 & $6.005,4$ \\
\hline 2009 & $1.832,3$ & 504,3 & 7,8 & 763,5 & 207,4 & 257,4 & $1.879, \mathrm{O}$ & 648,9 & 24,5 & $6.125,1$ \\
\hline 2010 & $1.842,5$ & 575,9 & 12,4 & 773,8 & 176,2 & 212,6 & $1.934,3$ & 570,9 & 14,6 & $6.113,2$ \\
\hline 2011 & $1.872,5$ & 582,9 & 9,6 & 725,0 & 147,6 & 222,2 & $2.195,1$ & 536,1 & 13,8 & $6.304,8$ \\
\hline 2012 & $1.968,2$ & 584,0 & 8,7 & 754,5 & 158,0 & 242,2 & $2.130,4$ & 565,9 & 12,9 & $6.424,8$ \\
\hline 2013 & $2.151,2$ & 623,0 & 6,5 & 826,3 & 206,3 & 211,6 & $2.090,6$ & 535,1 & 13,7 & $6.664,2$ \\
\hline 2014 & $2.278,1$ & 655,4 & 3,8 & 783,6 & 224,4 & 225,3 & $2.167,4$ & 570,8 & 12,4 & $6.921,1$ \\
\hline 2015 & $2.339,5$ & 689,3 & 3,6 & 788,8 & 190,8 & 241,4 & $2.230,8$ & 634,8 & 21,6 & $7.140,6$ \\
\hline
\end{tabular}

Fuente: INEC, Encuestas de empleo, subempleo y desempleo de varios años.

de evaluaciones de impacto de las políticas para tener mayor certeza sobre esta hipótesis, lo cual está fuera del alcance de este estudio. No obstante, en términos descriptivos, se observa que entre 2007 y 2014 las tasas de crecimiento económico promedio anual de las principales ramas económicas no petroleras están poco correlacionadas con las variaciones de la incidencia del empleo informal (ver Tabla 4). El coeficiente de correlación es bajo (-0,085). ${ }^{6}$ Es decir, al parecer, las ramas con mayor crecimiento económico no han reducido relativamente más el empleo informal ${ }^{7}$ (oIT, 2014, p. 6). 
De hecho, el empleo informal se redujo en todas las ramas de actividad económica. No obstante lo hizo en mayor medida en las ramas de servicios, particularmente en a) administración pública y defensa, b) en enseñanza, c) servicios sociales, y d) salud (ver Tabla 4); resultado que es consistente con lo que encuentra Banco Mundial (2014, p. 48). Esto último, posiblemente se debe, por un lado, a que los ministerios de Educación y Salud llevaron a cabo un proceso de formalización de las relaciones laborales con maestros y personal de salud contratados mediante aportes de los padres de familia, la comunidad o los gobiernos locales. Adicionalmente, en el Ministerio de Educación constaba un grupo de docentes denominados educadores comunitarios que recibían únicamente una bonificación mensual inferior al salario mínimo y no tenían afiliación a la seguridad social. La disposición transitoria decimonovena de la Constitución de 2008 dispuso que en el transcurso de tres años el Estado diseñe las políticas para la regularización de la planta docente de educación popular. Por otra parte, en el período se amplió el número de maestros, personal de salud y policías. Al respecto, Banco Mundial (2014) afirma que:

Otros sectores relacionados al sector público — como Enseñanza y Servicios sociales y de Salud- registraron importantes descensos en la informalidad, en áreas tanto urbanas como rurales, lo que resulta consistente con una campaña gubernamental para formalizar a los trabajadores del sector público. (p. 48)

Por último, la eliminación de la tercerización laboral, que se explica luego, implicó que varias empresas públicas contraten directamente e incluyan en su nómina a trabajadores que laboraban en las empresas tercerizadoras, excepto el personal de seguridad y limpieza. El empleo informal entre los asalariados públicos urbanos disminuyó de 9,2\% a 0,7\% (ver Tabla 3). Así, el aumento del empleo público formalizó empleo informal y agregó más formalidad al crecimiento del empleo. Al 2014, las ramas económicas con mayor empleo informal son la construcción, electricidad, gas y agua, agricultura, ganadería, caza y pesca, y alojamiento y servicios de comida (74,5\%, 69,1\% y 66,7\% respectivamente). En contraste, las ramas con menor tasa de empleo informal son administración pública y defensa, enseñanza y servicios sociales y de salud, actividades profesionales y técnicas (0,8\%, 10,1\% y 24,0\% respectivamente) (ver Tabla 4).

La tasa de empleo informal es mayor en los establecimientos de menor tamaño, se redujo de forma generalizada en todo tipo de establecimientos pero disminuyó relativamente más en las empresas más grandes. En efecto, cayó en términos relativos un 80\% en las empresas de cien o más empleados, al pasar de 24,4\% a 4,8\% (ver Tabla 5). Las empresas más grandes son más formales y están en capacidad de sufragar los costos de la formalización, mientras las más pequeñas, generalmente de baja productividad, tienen mayor dificultad de cubrir esos costos y cumplir con las regulaciones. Además, las empresas de menos de treinta empleados no alcanzan el número suficiente de trabajadores (30, según los artículos 442 a 447 del Código del Trabajo) para formar sindicatos, los cuales pueden ser mecanismos institucionales para presionar por la formalización del empleo. Esta situación es una gran limitante en un país como Ecuador en el que al año 2015 dos terceras partes de la población ocupada se encuentra en establecimientos de menos de 10 empleados. 
Tabla 3. Tasas de empleo informal urbano según categoría de trabajo (\%)

\begin{tabular}{lrrrrrrrrrrr}
\hline CATEGORÍA & 2007 & 2008 & 2009 & 2010 & 2011 & 2012 & 2013 & 2014 & 2015 & VA & VR \\
\hline Cuenta propia & 78,1 & 75,5 & 74,0 & 72,6 & 71,8 & 70,0 & 69,3 & 70,0 & 71,4 & $-6,7$ & $-8,6$ \\
Patrono & 31,1 & 31,9 & 26,9 & 22,5 & 24,9 & 25,3 & 17,2 & 21,1 & 24,4 & $-6,7$ & $-21,4$ \\
Trabajador auxiliar & 100,0 & 100,0 & 100,0 & 100,0 & 100,0 & 100,0 & 100,0 & 100,0 & 100,0 & 0,0 & 0,0 \\
Asalariado privado & 66,9 & 63,8 & 58,4 & 52,3 & 44,2 & 40,6 & 43,1 & 42,5 & 41,2 & $-25,7$ & $-38,4$ \\
Servicio doméstico & 87,5 & 86,9 & 83,1 & 77,5 & 65,8 & 71,1 & 64,6 & 58,8 & 55,3 & $-32,2$ & $-36,8$ \\
Asalariado público & 9,2 & 12,4 & 9,5 & 8,2 & 4,6 & 4,1 & 1,5 & 1,2 & 0,7 & $-8,5$ & $-91,9$ \\
Total & 65,1 & 62,8 & 59,8 & 55,0 & 51,4 & 48,9 & 48,4 & 48,8 & 48,4 & $-16,7$ & $-25,7$ \\
\hline
\end{tabular}

Fuente: INEC (2007-2015). Nota: VA = Variación absoluta; VR = Variación relativa.

Tabla 4. Tasas de variación del empleo informal urbano y tasas de crecimiento según ramas económicas no petroleras

\begin{tabular}{lcccccc}
\hline & \multicolumn{7}{c}{ EMPLEO INFORMAL } & \multicolumn{2}{c}{ VAB } \\
\cline { 2 - 7 } RAMA DE ACTIVIDAD ECONóMICA & 2007 & 2014 & VA & VR & VPA & CPA 2007-2014 \\
\cline { 2 - 7 } Agricultura, ganadería, caza y pesca & A & B & & & & 3,1 \\
Manufactura (incluida refinería) & 83,9 & 69,1 & $-14,8$ & $-17,6$ & $-2,7$ & 2,9 \\
Construcción, electricidad, gas y agua & 64,1 & 47,5 & $-16,6$ & $-25,9$ & $-4,2$ & 9,6 \\
Comercio & 85,0 & 74,5 & $-10,5$ & $-12,3$ & $-1,9$ & 4,9 \\
Alojamiento y servicios de comida & 72,4 & 55,9 & $-16,5$ & $-22,8$ & $-3,6$ & 5,9 \\
Transporte, correo y comunicaciones & 77,6 & 66,7 & $-10,9$ & $-14,0$ & $-2,1$ & 7,1 \\
Actividades profesionales y técnicas & 67,7 & 51,7 & $-16,0$ & $-23,6$ & $-3,8$ & 4,4 \\
Adm. pública y defensa & 46,9 & 24,0 & $-23,0$ & $-49,0$ & $-9,2$ & 6,6 \\
Enseñanza y servicios sociales y de salud & 8,1 & 0,8 & $-7,3$ & $-89,9$ & $-27,9$ & 4,7 \\
Servicio doméstico & 31,4 & 10,1 & $-21,2$ & $-67,7$ & $-14,9$ & 3,3 \\
Otros servicios & 87,5 & 58,5 & $-29,0$ & $-33,1$ & $-5,6$ & 2,9 \\
Total & 63,6 & 42,5 & $-21,1$ & $-33,2$ & $-5,6$ & 2,6 \\
Coeficiente de correlación & 65,1 & 48,8 & $-16,3$ & $-25,0$ & $-4,0$ & 5,1
\end{tabular}

Fuente: INEC, Encuestas de empleo, subempleo y desempleo de varios años. Nota: VAB = Valor agregado bruto; VA = Variación absoluta $(\mathrm{c}=\mathrm{b}-\mathrm{a}) ; \mathrm{VR}=$ Variación relativa $(\mathrm{d}=(\mathrm{b} / \mathrm{a}-1)) ; \mathrm{VAP}=$ Variación promedio anual $\left(\mathrm{e}=(\mathrm{b} / \mathrm{a})^{\wedge}(1 / 7)-1\right) ; \mathrm{CPA}=$ Crecimiento promedio anual (geométrico).

\section{POLÍTICAS PÚBLICAS FAVORABLES AL TRABAJADOR}

Desde 2007 se impulsó un conjunto de políticas favorables a los trabajadores. Por ejemplo, el Mandato Constituyente N. 8 eliminó varias formas de precarización del trabajo; además, se implementaron políticas activas de salario mínimo y de fiscalización del cumplimiento por parte de los empleadores de su obligación de afiliar a sus trabajadores a la seguridad social (OIT, 2014, pp. 6, 7). El Mandato Constituyente N. ${ }^{\circ}$, emitido en mayo de 2008 por la Asamblea Nacional Constituyente encargada de redactar la nueva Constitución, eliminó la tercerización, ${ }^{8}$ 
la intermediación laboral y la contratación por horas. ${ }^{9}$ El artículo 2 eliminó y prohibió la contratación laboral por horas y garantizó la jornada parcial con estabilidad, protección integral, remuneración proporcional y derecho a todos los beneficios de ley, afiliación a la seguridad social y fondo de reserva ${ }^{10}$ (Asamblea Constituyente, 2008, pp. 2, 3). El Código Orgánico de la Producción, Comercio e Inversiones, expedido a finales de 2010, flexibilizó relativamente las restricciones a los contratos temporales, permitiéndolos para períodos de alta demanda y producción, reemplazo temporal de personal ausente y para actividades estacionales.

En el período 2007-2014 el salario mínimo en dólares corrientes aumentó anualmente, en promedio, 10,5\% (pasó de USD 170 mensuales en 2007 a USD 340 en 2014), mientras que la tasa de inflación anual promedió un 4,4\% y el crecimiento anual de la productividad laboral media un 3,3\%. La política salarial consistió en aumentar el salario mínimo en el equivalente a la suma de la tasa de inflación, más el crecimiento de la productividad laboral y más un factor de equidad con el fin de cerrar la brecha entre este y el salario digno. La Constitución de 2008, en el artículo 328, estableció que la «remuneración será justa, con un salario digno que cubra al menos las necesidades básicas de la persona trabajadora, así como las de su familia», y en su disposición transitoria vigésima quinta, que la «revisión anual del salario básico se realizará con carácter progresivo hasta alcanzar el salario digno de acuerdo con lo dispuesto en esta Constitución. El salario básico tenderá a ser equivalente al costo de la canasta familiar» (Asamblea Constituyente, 2008, p, 154).

Por su parte, los artículos 8 y 9 del Código Orgánico de la Producción, Comercio e Inversiones definieron al salario digno como el costo de la canasta básica familiar dividido para el número de perceptores del hogar, y como sus componentes, entre otros, básicamente al sueldo o salario mensual y la parte proporcional del décimo tercero, décimo cuarto, participación en utilidades y los fondos de reserva. Es necesario señalar que esta interpretación no es aceptada por las organizaciones de trabajadores, quienes defienden la interpretación literal del artículo 328 de la Constitución. Entre 2007 y 2014 mejoró la distribución funcional del ingreso a favor de los trabajadores al aumentar la participación de las remuneraciones en el valor agregado bruto de $33 \%$ a $39 \%$.

\section{CONSTITUCIÓN DE 2008, PLANES NACIONALES \\ PARA EL BUEN VIVIR Y AGENDAS SECTORIALES}

En la nueva Constitución de la República, aprobada mediante referéndum el 28 de septiembre de 2008, se ampliaron y fortalecieron los derechos económicos y sociales de la población, entre ellos el derecho a la seguridad social. En particular, el artículo 327 establece que será penalizado el incumplimiento de obligaciones y el fraude en materia laboral. ${ }^{11}$ La política activa favorable a la afiliación de los trabajadores a la seguridad social se evidenció también en los distintos niveles de planificación del gobierno ecuatoriano, desde el Plan Nacional para el Buen Vivir hasta las políticas ministeriales.

El Plan Nacional para el Buen Vivir 2009-2013 incorporó la política de ampliar la cobertura de la seguridad social, generar condiciones dignas para el trabajo y velar por el cumplimiento de los derechos laborales. ${ }^{12}$ Estableció como meta 1.2.1 Alcanzar el 40\% de personas con seguro 
Tabla 5. Tasa de empleo informal por tamaño de empresa (\%)

\begin{tabular}{lcccc}
\hline TAMAÑO DE EMPRESA & 2007 & 2015 & VARIACIÓN ABSOLUTA & VARIACIÓN RELATIVA \\
\hline De 1 a 4 empleados & 87,7 & 79,4 & $-8,3$ & $-9,5$ \\
De 5 a 9 empleados & 85,8 & 70,3 & $-15,5$ & $-18,1$ \\
De 10 a 49 empleados & 68,1 & 37,3 & $-30,8$ & $-45,2$ \\
De 50 a 99 empleados & 49,1 & 18,5 & $-30,6$ & $-62,3$ \\
De 100 o más empleados & 24,4 & 4,8 & $-19,6$ & $-80,1$ \\
Total & 74,1 & 57,3 & $-16,8$ & $-22,6$ \\
\hline
\end{tabular}

Fuente: INEC (2007-2015).

Social hasta el 2013 (SENPLADES, 2009, p. 151; OIT, 2014, p. 7). Estas políticas y metas fueron recogidas tanto en la Agenda Social 2009-2011 como en la Agenda Social 2012-2013 del Consejo Sectorial de Desarrollo Social, que corresponde al segundo nivel del sistema de planificación nacional y comprende las políticas del gabinete social del Gobierno (Ministerio Coordinador de Desarrollo Social, 2010, p. 37; Ministerio Coordinador de Desarrollo Social, 2012, p. 37).

El Ministerio de Relaciones Laborales, ahora Ministerio del Trabajo, ajustó sus políticas institucionales al Plan Nacional para el Buen Vivir (orT, 2014, p. 7). De acuerdo con su informe de rendición de cuentas del año 2010, estableció como su objetivo estratégico institucional 3: «Desarrollar e implantar un sistema de evaluación y control público y privado sobre la aplicación de las Leyes, normativa ministerial y el respeto de los derechos fundamentales de servidores y trabajadores» (Ministerio de Relaciones Laborales, 2010, p. 4). El nuevo Plan Nacional para el Buen Vivir 2013-2017, en el objetivo 9, Garantizar el trabajo digno en todas sus formas, plantea la meta 9.7, aumentar la PEA de 15 años o más afiliada a la seguridad social contributiva de 41,4\% en 2012 al 60,0\% en 2017, y a nivel rural de 32,7\% al 50,0\% (SENPLADES, 2013, p. 289).

Además, las instituciones públicas están obligadas por la Ley de Seguridad Social de 2001 a recabar de las empresas constructoras las certificaciones de que se encuentran al día en el pago de aportes al Instituto Ecuatoriano de Seguridad Social (IESs). ${ }^{13}$ Para cumplir con estas disposiciones, las entidades públicas incluyen en las cláusulas contractuales con las empresas constructoras privadas la obligación de presentar dichos certificados. ${ }^{14}$ Esta normativa debería haber contribuido a formalizar a los trabajadores de la construcción en un período de crecimiento económico basado en el aumento de la inversión pública en infraestructura (OIT, 2014, p. 7). La inversión del sector público no financiero pasó de 6,1\% del PIB en 2007 a 13,9\% del PIB en 2014 y los datos de las encuestas nacionales de empleo muestran un aumento de los ocupados en el sector de la construcción entre 2007 y 2014 de aproximadamente 80 ooo trabajadores. Sin embargo, la rama de la Construcción es la que muestra la menor reducción relativa del empleo informal, apenas 12,3\% (ver Tabla 4). Al respecto, Banco Mundial (2014) encuentra que «A pesar de un aumento de contratos públicos en el sector Construcción, la informalidad en Construcción mostró un mediocre descenso de 9\% entre 2007 y 2013» (p. 48).

Tanto la Agenda para la Transformación Productiva 2010-2013 del Consejo Sectorial de la Producción como el Código Orgánico de la Producción, expedido en diciembre de 2010, ${ }^{15}$ plantean a los empresarios el cumplimiento de las cuatro éticas: ética con los trabajadores, ética 
con la comunidad, ética con el Estado y ética con el medio ambiente. La ética con los trabajadores implica que los empleadores cumplan sus obligaciones laborales y de seguridad social con sus trabajadores ${ }^{16}$ (Ministerio Coordinador de la Producción, Empleo y Competitividad, 2010, pp. 15, 77). El Ministerio de Industrias y Productividad tiene a su cargo los sellos «Hace Bien» $y$ «Hace Mejor» para certificar a las empresas que cumplen con las cuatro éticas y ha definido una lista de certificadoras y consultores calificados para su implementación. Sin embargo, hasta finales de 2015, solo once empresas han sido certificadas con el Sello «Hace Bien» y dos con el sello «Hace Mejor», todas ellas grandes empresas.

\section{PENALIZACIÓN DE LA NO AFILIACIÓN A LA SEGURIDAD SOCIAL}

El presidente Rafael Correa convocó a un referéndum y consultar popular que se celebró el 7 de mayo de 2011. La quinta pregunta de la consulta popular consultó a la población lo siguiente:

¿Está usted de acuerdo con que la Asamblea Nacional, sin dilaciones dentro del plazo establecido en la Ley Orgánica de la Función Legislativa, a partir de la publicación de los resultados del plebiscito, tipifique como infracción penal la no afiliación al Instituto Ecuatoriano de Seguridad Social de los trabajadores en relación de dependencia?

Los resultados se proclamaron oficialmente el 12 de julio de 2011 y se publicaron el 13 de julio de 2011 en el Registro Oficial N. ${ }^{\circ}$ 490. En la pregunta 10, los votos favorables al sí alcanzaron el 55,02\% de los votos válidos y los favorables al no el 44,97\% (OIT, 2014, p. 7). La tipificación como infracción penal demoró y recién el 10 de febrero de 2014 la Asamblea Nacional expidió, mediante publicación en el Suplemento al Registro Oficial N. ${ }^{\circ}$ 180, el Código Orgánico Integral Penal que incluye las sanciones y multas por la no afiliación al IEss. Son tres artículos, el 242, que reemplaza al artículo 78 de la actual Ley de Seguridad Social, ${ }^{17}$ y los artículos 243 y 244 que son nuevos (OIT, 2014, p. 7). El artículo 242 establece una pena privativa de libertad de uno a tres años por la retención ilegal de las aportaciones a la seguridad social y la clausura del local o establecimiento hasta que se cancele los valores adeudados en caso de encontrarse responsabilidad penal de la persona jurídica. ${ }^{18}$

Por su parte, el artículo 243 tiene relación con las empresas legalmente constituidas que no afilien a sus trabajadores a la seguridad social. En este caso la empresa, en su calidad de persona jurídica, puede ser intervenida y sancionada con una multa de 3 a 5 salarios básicos unificados del trabajador en general por cada empleado no afiliado. ${ }^{19} \mathrm{El}$ salario básico unificado del trabajador en general corresponde al salario mínimo y en el año 2014 ascendió a USD 340 dólares mensuales, que equivalió en términos anuales al 64,8\% del PIB per cápita (USD 6297). Por último, el artículo 244 fija la pena privativa de libertad de 3 a 7 días para los empleadores por la falta de afiliación a la seguridad social de sus trabajadores..$^{20}$ Las penas y multas previstas en los artículos 243 y 244 se imponen siempre que la persona infractora no abone el valor en mora dentro del término de cuarenta y ocho horas después de haber sido notificada (orT, 2014, p. 7).

Si bien la tipificación de la no afiliación a la seguridad social como infracción penal demoró más de cinco años desde la promulgación de la nueva Constitución a finales de 2008, el aumento en la afiliación y la reducción del empleo informal observado en este período sugieren 
que la sola posibilidad de la penalización modificó el comportamiento de los empresarios y los indujo a afiliar a sus trabajadores, cambio de conducta que se habría ahondado con la Consulta Popular de 2011 y la discusión en la Asamblea del nuevo Código Integral Penal (oIT, 2014, p. 7).

$\mathrm{Al}$ respecto, el Banco Mundial (2012, p. 70) afirma que el resultado de la consulta popular incrementó los costos de la informalidad y que la seriedad del mensaje de la penalización enviado por las autoridades probablemente estimuló el incremento en la afiliación de los trabajadores a la seguridad social aún antes de que las infracciones penales entren en vigencia. De igual modo, Goñi (2013, p. 5) afirma que la protección laboral dispuesta por la nueva Constitución y la aplicación más rigurosa de las regulaciones laborales probablemente indujeron a la formalización de las relaciones laborales. Asimismo, el Banco Mundial (2014) afirma que «Si bien la ley [Código Orgánico Integral Penal] no se implementó sino a comienzos del 2014, poco después del referéndum se observó un importante incremento en la tasa de afiliaciones al IESS» (p. 84).

\section{INSPECTORÍAS DEL TRABAJO Y CONTROL DEL CUMPLIMIENTO DE LAS OBLIGACIONES LABORALES}

El gobierno, a través del Ministerio de Relaciones Laborales y el Instituto Ecuatoriano de Seguridad Social, ${ }^{21}$ impulsó desde el año 2009 un programa activo de inspectorías del trabajo basado en la difusión de los derechos y obligaciones laborales a través de los medios de comunicación y en la supervisión in situ de hogares y empresas a través de inspectores de las direcciones regionales de esa entidad. En el año 2010 se emprendió la campaña Trabajo Doméstico Digno que se enfocó en fiscalizar directamente en las viviendas de los barrios de clase media y alta el cumplimiento por parte de los patronos de las condiciones contractuales y de los beneficios de ley para las empleadas domésticas. A partir de 2011, la campaña se denominó Trabajo Digno y añadió la fiscalización directa en las empresas del cumplimiento de las condiciones laborales con los trabajadores en general. En el caso de que los patronos incumplan, deben pagar multas y regularizar la situación laboral del empleado. El número de inspectores aumentó un 277\% entre 2006 y 2011, al pasar de 65 a 245 inspectores. (OIT, 2014, p. 9). La reactivación de las inspectorías del trabajo se basó en la Disposición Final Segunda del Mandato Constituyente N. ${ }^{\circ}$, de mayo de 2008 , que dispuso que:

Para un efectivo control y cumplimiento de las disposiciones del presente mandato, que consolide los derechos fundamentales de los trabajadores y la seguridad jurídica de los empleadores, el Ejecutivo fortalecerá la infraestructura organizacional, administrativa y financiera del Ministerio de Trabajo y Empleo.

Según el Informe de Rendición de Cuentas de 2012, el Ministerio de Relaciones Laborales (MRL) realizó 23.744 inspecciones en ese año y sensibilizó a 548.00o trabajadores (Ministerio de Relaciones Laborales, 2012, p. 6). En 2011 realizó 26.764 inspecciones (MRL, 2011, p. 4) y 17.820 en el 2010 (MRL, 2010, p. 38). Hasta septiembre de 2013, el ministerio había realizado 26.207 inspecciones (MRL, 2013, p. 3). En años previos al 2010, el número de inspecciones bordeaba apenas las 500 anuales y se basaba en un modelo pasivo en función de las denuncias 
recibidas. Por su parte, el informe de rendición de cuentas 2011 del IEss (2011, pp. 100, 101) señala que el número de empleadores registrados aumentó de 140.759 en 2008 a 320.823 en 2011 (OIT, 2014, p. 9). En este último año la tasa de crecimiento fue de $46,7 \%$ respecto de un total de empleadores en el 2010 de 218.752. Asimismo, el número de afiliados al seguro general obligatorio, que es el régimen general de la seguridad social, subió en 126\% entre 2006 y 2015, al pasar de 1.401 .935 a 3.175 .284 .

Hay dos estudios empíricos del Banco Mundial que analizan los efectos de las inspectorías. El primero, basado en una encuesta realizada entre mayo y junio de 2011 a una muestra de 1.200 micro y pequeñas empresas (de 1 a 50 empleados) en las ciudades de Quito, Guayaquil, Tulcán y Machala, encontró que el 8,5\% de las empresas afirmaron haber sido inspeccionadas en el último año por el Ministerio de Relaciones Laborales y el 11,1\% por el Instituto Ecuatoriano de Seguridad Social, ${ }^{22}$ con una correlación positiva entre las inspecciones de estas dos entidades de 0,50; es decir, que si alguna de ellas realizó una inspección a una empresa, aumenta la probabilidad de que la misma empresa reciba la inspección de la otra (Banco Mundial, 2012, pp. 66-70). Las inspecciones aumentaron la probabilidad de que las empresas cumplan las obligaciones laborales, aunque no todas las que recibieron inspecciones lo hicieron. El estudio comparó las empresas que fueron inspeccionadas en el último año con las que no y encontró que el $50 \%$ de las primeras cumplió con la afiliación a la seguridad social de sus trabajadores, frente a solo el $20 \%$ de las segundas. Finalmente, el estudio encontró que entre empresas con similares características institucionales y del propietario, el impacto marginal sobre el porcentaje de empleados afiliados a la seguridad social fue positivo y mayor en aquellas inspeccionadas por el IEss $(0,17)$ que en aquellas inspeccionadas por el MRL (0,15) (OIT, 2014, p. 9).

El segundo estudio se refiere a las inspecciones y al cruce de información entre el Ministerio de Relaciones Laborales y el Servicio de Rentas Internas como determinantes de una mayor formalización:

El Gobierno ha tomado varias medidas para asegurar que los empleadores cumplan la ley, incrementando significativamente el número de inspecciones del Ministerio de Relaciones Laborales y realizando campañas masivas de comunicación sobre la necesidad de respetar los derechos de los trabajadores y ofrecer un pago digno. Asimismo, el Ministerio de Relaciones Laborales está ahora verificando la información del empleo con el Servicio de Rentas Internas (SRI), lo que ha incrementado la formalización de manera importante. (Banco Mundial, 2014, p. 84)

El Banco Mundial realizó una descomposición econométrica de los cambios en la probabilidad de informalidad en cambios en las características de los trabajadores y cambios en los parámetros o la propensión a ser informal. Encontró que la reducción de la informalidad de los trabajadores asalariados se debió principalmente a cambios en los parámetros; es decir, a la disminución de la propensión a ser informal (Banco Mundial, 2014, pp. 62, 63). Concluyó que esto «sugiere que los cambios en las regulaciones del mercado laboral y la mayor aplicación de las normas sí tuvieron importancia en la reducción de la informalidad» (Banco Mundial, 2014, p. 10). En el caso de los trabajadores por cuenta propia, encontró que la reducción de la informalidad fue pequeña y que se debió principalmente a cambios en las características de 
los trabajadores. En resumen, la reactivación de las inspectorías laborales aumentó la probabilidad de que los empleadores sean descubiertos incumpliendo sus obligaciones y, por otro, la expectativa de la penalización incrementó el costo esperado de infringir la ley.

\section{EMPLEO DOMÉSTICO}

Un énfasis especial recibieron las políticas dirigidas a mejorar la calidad del empleo doméstico remunerado. Se aumentó el salario mínimo de las empleadas domésticas y se lo homologó con el salario mínimo de los trabajadores en general. ${ }^{23}$ Además se exigió que los patronos las afilien a la seguridad social, respeten el horario de trabajo reconozcan y otorguen las vacaciones de ley, paguen las horas extras, el fondo de reserva y los décimos terceros y cuartos sueldos (OIT, 2014, p. 10).

Como se describió antes, la campaña Trabajo Doméstico Digno del Ministerio de Relaciones Laborales emprendió, luego de las etapas de información y difusión de derechos y obligaciones laborales, inspecciones directas en las viviendas a fin de verificar mediante entrevistas con las empleadas domésticas el cumplimiento de sus derechos laborales. En la entrada de las viviendas que cumplían con las obligaciones laborales los inspectores ponían un sello de Trabajo Digno, a la usanza de los censos de población y vivienda (OIT, 2014, p. 10).

Con esta política activa, el Servicio doméstico pasó de ser la rama de actividad económica con mayor incidencia de empleo informal en el 2007 a ser la cuarta en el 2014 (ver Tabla 4). Como se indicó antes, si bien aumentó el porcentaje de empleadas domésticas con afiliación a la seguridad social, en términos absolutos disminuyó su número de 201.000 a 158.000 entre 2007 y 2012. Este comportamiento posiblemente indica que hubo hogares que despidieron a las empleadas domésticas en esos años porque no estuvieron en capacidad de sufragar el aumento del salario mínimo y los costos de la afiliación a la seguridad social o debido al temor de incurrir en infracciones penales por la no afiliación (OIT, 2014, p. 10). Al respecto, Bosch, Melguizo y Pagés (2013) señalan que las inspecciones aumentaron la afiliación pero también destruyeron empleos:

Si bien es cierto que la iniciativa logró que un mayor porcentaje de trabajadores domésticos se afiliara a la seguridad social, también es verdad que se destruyeron muchos empleos para personas que no tienen demasiadas opciones en el mercado laboral. En resumen, la evidencia, aunque escasa, tiende a confirmar los efectos que la teoría presume para una mayor fiscalización en el mercado de trabajo. Por una parte, el incremento en la creación de trabajo formal. Por la otra, una reducción en el empleo total. Este último hecho obedece a que algunos trabajos que operan informalmente no son rentables si tienen que regularizarse y por lo tanto dejan de existir. (p.136)

Sin embargo, en los años 2013 y 2014 el número de empleadas domésticas volvió a subir (206.000 y 224.00o respectivamente), para caer nuevamente en 2015 (190.000). La recuperación del número de empleadas domésticas estuvo acompañado de menos horas promedio trabajadas (Banco Mundial, 2014, p. 41). Sobre la reducción temporal del empleo doméstico y la posterior recuperación, el Banco Mundial (2014) señala que probablemente se debió a los efectos de la crisis financiera global: 
Es probable que la ayuda doméstica sea uno de los primeros gastos que cortan los hogares que afrontan un recorte presupuestal, y cualquier aumento de costos podría llevar a las familias a buscar alternativas más baratas (por ejemplo, trabajar ellos mismos). Esto parece haber ocurrido como resultado de la crisis financiera global: el número de empleados domésticos disminuyó después de 2009, pero retornó a los niveles anteriores a la crisis en el 2013. (p. 41)

La política salarial y las inspectorías del trabajo fueron acompañadas a finales de 2012 con la promulgación de la Ley orgánica para la defensa de los derechos laborales que en su artículo 5 deroga el artículo 269 del Código de Trabajo que establecía que los empleados domésticos tienen derecho a un día de descanso cada dos semanas de servicio y en su artículo 6 garantiza a los empleados y trabajadores domésticos los mismos beneficios que los trabajadores en general, especialmente en lo relativo a la jornada laboral y los días de descanso. ${ }^{24}$

\section{INCENTIVOS A LA AFILIACIÓN A LA SEGURIDAD SOCIAL}

Un conjunto de reformas que amplían el acceso al seguro de salud del iess y el acceso a los préstamos del Banco del IESs (BIESs) ha vuelto más atractivo el estar afiliado a la seguridad social (OIT, 2014, p. 8): ampliación de la cobertura del seguro de salud a los hijos menores de 18 años con cargo a las mismas aportaciones personales y patronales del afiliado y a los cónyuges de los afiliados a través de un aporte adicional equivalente al 3,41\% de la remuneración; ${ }^{25}$ disminución del período de carencia para causar el derecho a los beneficios del seguro de salud de 6 a 3 meses; ${ }^{26}$ ampliación de la cobertura de la atención médica de salud mediante la derivación de pacientes a clínicas, hospitales y centros médicos privados, instituciones que reciben del IEss el pago por las prestaciones de salud realizadas sobre la base de un tarifario; ${ }^{27}$ reanudación y ampliación del volumen de créditos prendarios, quirografarios e hipotecarios para los afiliados a través del BIESs; ${ }^{28}$ y mejoramiento de los servicios, infraestructura y equipamiento de los centros de salud y hospitales del IEss. Además, el IEss implementó trámites en línea a través de su página web para la afiliación de trabajadores en general y empleadas domésticas y para el pago de los aportes (OIT, 2014, p. 8). De igual manera, el Ministerio de Relaciones Laborales facilitó el registro de contratos a través de su página web.

Con el fin regularizar la afiliación de los trabajadores a la seguridad social, la disposición transitoria segunda de la Ley Orgánica para la Defensa de los Derechos Laborales del año 2012 facultó a los empleadores por un período de seis meses a afiliar extemporáneamente a sus trabajadores al IESs sin sanciones ni recargos por multas. ${ }^{29}$ Sin embargo, la mora patronal se estimó en USD 500 millones a finales de 2015, de los cuales USD 375 millones correspondían a aportes y USD 125 millones a intereses y multas. En el contexto de la recesión económica de 2015, los artículos 22 al 30 de la Ley Orgánica de Incentivos para Asociaciones Público Privadas y la Inversión Extranjera, Publicada en el Suplemento al Registro Oficial N. ${ }^{\circ} 652$ de 18 de diciembre de 2015, dispusieron la remisión de intereses, multas y recargos por mora patronal con el IESS, previa cancelación de los valores por aportes adeudados, como un mecanismo para conseguir ingresos de caja pero reduciendo los pasivos del sector patronal.

La ampliación en el 2010 de la cobertura legal del seguro de salud a hijos menores de 18 años y cónyuges implicó que se duplique el total de la población asegurada de 3146198 en 2009 a 
6.380.927 en 2010 y a 8.151.385 en julio de 2013. Así, la cobertura legal pasó de $20 \%$ de la población total en 2007 a 52\% en $2013^{30}$ (OIT, 2014, p. 8). Sobre esto, Banco Mundial (2012) sostiene que otras razones del incremento del porcentaje de trabajadores afiliados a la seguridad social:

Probablemente sean los recientes cambios que permiten la afiliación de trabajadores a tiempo parcial, cierta relajación de las normas que exigen un período mínimo de empleo continuo antes de poder tener acceso a las prestaciones y la posibilidad de recurrir a servicios médicos tanto en centros públicos como privados. (p. 70)

Plantea, además, que estas reformas y el control más estricto a los empleadores luego de la consulta popular que dispone la penalización de la no afiliación «pueden haber incrementado los índices de afiliación y la percepción del valor de la seguridad social» (Banco Mundial, 2012, p. 70). Así mismo, Goñi (2013) afirma que los préstamos hipotecarios han sido un incentivo novedoso para ampliar la cobertura del sistema previsional:

Algunos intentos de expandir la cobertura a través de enfoques más novedosos han sido hechos en países como Ecuador, donde el Instituto de Seguridad Social tiene un banco que ofrece préstamos hipotecarios en términos competitivos a los trabajadores que califican y que han aportado regularmente al fondo de pensiones. (p. 7)

El Seguro Social Campesino también aumentó su cobertura de 704.000 a 1,1 millones de beneficiarios, jubilados y afiliados entre 2007 y 2014. En particular, los afiliados se incrementaron de 164.000 a 330.000 en ese período. Sin embargo, las reformas descritas han ocasionado también un exceso de demanda de servicios de atención de salud, lo cual ha puesto tensión a una oferta insuficiente y ha generado un desfinanciamiento del seguro de salud (déficit de USD 550 millones en 2015). De hecho, en 2015 se modificó transitoriamente la distribución de los aportes, sin afectar el aporte total, destinando una mayor proporción al seguro de salud -resolución CD 501, de 13 de noviembre de 1015, del Consejo Directivo del IEss-. En el caso de los trabajadores del sector privado bajo relación de dependencia, para el año 2016, se redujeron el aporte al seguro de invalidez, vejez y muerte de $9,74 \%$ a 5,86\% y el aporte al seguro de riesgos del trabajo de 0,55\% a 0,20\% y se aumentó el aporte al seguro de salud de 5,71\% a $9,74 \%$. Esta distribución se revertirá paulatinamente año a año hasta alcanzar en el año 2021 un $10,46 \%$ para el seguro de invalidez, vejez y muerte, un 5,16\% para el seguro de salud y un $0,20 \%$ para el seguro de riesgos del trabajo.

Mediante la Ley de Justicia Laboral y Reconocimiento del Trabajo en el Hogar, de abril de 2015, se faculta la afiliación de las trabajadoras del hogar no remuneradas en el seguro social obligatorio con la cobertura de las contingencias de vejez, muerte e invalidez y bajo una modalidad de cotizaciones de la unidad económica familiar según su nivel de ingreso complementadas con un subsidio del Estado a las aportaciones individuales. La ley también eliminó el subsidio anual del gobierno central al IEss equivalente al 40\% de las pensiones comprometiéndose a pagar el saldo faltante únicamente cuando este haga falta y fijó que el incremento anual de las pensiones sería de acuerdo a la inflación. Mientras la eliminación del subsidio anual afecta la sostenibilidad actuarial del fondo de pensiones, el aumento anual de las pensiones según la tasa de inflación del año anterior la mejora, ya que el mecanismo vigente 
previamente incrementaba las pensiones por sobre la inflación a un grupo importante de pensionistas según una tabla escalonada. ${ }^{31}$ Adicionalmente, la eliminación del subsidio anual a las pensiones tiende a convertir en el tiempo al fondo de pensiones de uno de reparto con capitalización colectiva a uno de reparto simple, sin afectar la solidaridad del esquema entre afiliados y pensionistas.

Esta ley también faculta al Ministerio del Trabajo a establecer límites a las brechas remunerativas entre los gerentes y los trabajadores de menor remuneración en la empresa, elimina el contrato a plazo fijo, fortalece las garantías laborales de los dirigentes sindicales, prohíbe el despido intempestivo de mujeres embarazadas y lo declara ineficaz, crea la figura de empresas vinculadas con el fin de que sean subsidiariamente responsables de obligaciones laborales $y$, en el caso de que formen parte de una misma cadena de valor, con el fin de que se consideren como una sola para el reparto de utilidades a los trabajadores. Sin embargo, esta norma legal también estableció un límite de hasta 24 salarios básicos unificados al monto de las utilidades distribuidas a los trabajadores, debiendo destinarse el excedente, en caso de haberlo, al régimen de prestaciones solidarias de la Seguridad Social.

Varias organizaciones sociales, de trabajadores y políticas interpusieron demandas de inconstitucionalidad a distintos artículos de esta ley, especialmente a aquellos referidos al techo fijado a las utilidades de los trabajadores, los límites a las indemnizaciones de los servidores públicos, la eliminación del 40\% del subsidio estatal a las pensiones del IEss y el incremento de pensiones según la inflación (Audiencia por ley laboral se cumplió, 2016; Primera demanda contra la Ley de Justicia Laboral, 2015). También se cuestiona que la afiliación al IEss de las trabajadoras no remuneradas del hogar no cubra las contingencias de salud ni de acceso a los préstamos quirografarios e hipotecarios (Sexta demanda contra la Ley de Justicia Laboral en la Corte Constitucional, 2015).

\section{CONCLUSIONES E IMPLICACIONES DE POLÍTICA PÚBLICA}

El empleo informal disminuyó principalmente en el sector formal de la economía y, particularmente, en las empresas grandes y en las instituciones de gobierno. Aunque no hay evaluaciones de impacto rigurosas que identifiquen la relación causal entre cada una de las políticas implementadas y la reducción del empleo informal mediante métodos cuantitativos experimentales o cuasiexperimentales, la evidencia presentada apunta a que se debió a reformas legales e institucionales y a una política activa para hacer cumplir a los empleadores con sus obligaciones laborales. Éstas comprendieron políticas favorables al trabajador, aunque no sin contradicciones; cambios constitucionales y normativas que fortalecieron los derechos de los trabajadores y las obligaciones de los empleadores y que penalizaron la no afiliación a la seguridad social; el sistema nacional de planificación que orientó las políticas en sus distintos niveles hacia el aumento de la cobertura de la seguridad social; el cambio de modelo y la expansión de las inspectorías del trabajo para controlar en las empresas y las viviendas el goce de los derechos laborales; y reformas del Instituto Ecuatoriano de Seguridad Social que volvieron más atractivo para los trabajadores el estar afiliado y que facilitaron los trámites administrativos (OIT, 2014, p. 11). 
Las políticas estudiadas se concentraron principalmente en el sector formal de la economía y en los trabajadores en relación de dependencia. Una mayor extensión de la afiliación a la seguridad social y reducción del empleo informal requiere que los hacedores de política pública consideren la rigidez estructural a la baja del sector informal, el gran peso de las pequeñas empresas y de baja productividad, el aumento de los trabajadores por cuenta propia y la reducción de los patronos. Difícilmente se logrará la meta del 60\% de la PEA afiliada a la seguridad social al año 2017; de hecho a 2015 la cifra alcanzó únicamente 44,2\%. Aún está pendiente una reforma de la seguridad social que permita el acceso de los trabajadores independientes, los que tienen una alta tasa de empleo informal (71,4\% en 2015). Las políticas analizadas se concentraron principalmente en el empleo asalariado en relación de dependencia que representó al año 2015, incluidos los jornaleros, peones y empleadas domésticas, un 56,2\% del total de ocupados. No obstante, los asalariados privados y las empleadas domésticas aún tienen importantes niveles de empleo informal (41,2\% y 55,3\% respectivamente). Por otra parte, los mayores niveles de informalidad se encuentran en las empresas de menor tamaño, las cuales son la mayoría en el país $(66,9 \%)$. En efecto, las empresas de 1 a 4 empleados tienen una tasa de empleo informal de $79,4 \%$ y las 5 a 9 de $70,3 \%$, mientras que en las de 100 o más empleados la tasa es de apenas $4,8 \%$ (ver Tabla 5 ).

Debido al carácter dual de los salarios, al ser tanto fuente de demanda y costo de producción, la política activa de aumento de los salarios por sobre la productividad del trabajo luego de generar un efecto positivo de demanda efectiva pueden haber creado, junto con los mayores costos que implica la afiliación de los trabajadores, restricciones por el lado de la oferta, especialmente para micro, pequeñas y medianas empresas, las cuales por su baja productividad tienen mayor dificultad de sufragar los mayores costos laborales. Al respecto, el Banco Mundial (2014) afirma: «Estas políticas pueden ser efectivas para reducir la informalidad, siempre y cuando esta se origine únicamente de la falta de voluntad de cumplir, y no de la incapacidad de cumplir» (p. 10).

Asimismo, Goñi encuentra evidencia de efectos negativos de los incrementos de salarios mínimos en las ciudades más expuestas a estos cambios (ciudades con una mayor masa de trabajadores entre el viejo y el nuevo salario mínimo): se reduce la probabilidad de pasar de desempleado a asalariado formal, aumenta la probabilidad de permanecer como asalariado informal y aumenta la probabilidad de pasar de asalariado formal a asalariado informal (Goñi, 2013, pp. 18, 19). Igualmente, para Banco Mundial (2014) los costos salariales podrían estar afectando la creación de empleos formales de baja calificación:

El salario mínimo se está acercando a la media del salario, y es alto para los estándares internacionales con respecto a la productividad de los trabajadores [...]. Si bien es deseable tener como punto de referencia el concepto de un salario que permita vivir dignamente, un salario mínimo que se establece en la media del salario - y, por lo tanto, por encima de la productividad de muchos trabajadores- podría distorsionar los incentivos productivos, ser difícil de aplicar, y podría afectar la creación de empleos formales que requieren menor cualificación. Además de salarios más altos, los trabajadores formales acceden a beneficios no salariales de al menos el $40 \%$ del salario base, haciendo que los costos de formalización sean prohibitivos para muchas empresas pequeñas y medianas, sobre todo si la productividad de los trabajadores es baja. (pp. 11, 12) 
Si bien la reducción observada en el empleo informal es relevante (17 puntos porcentuales), su nivel sigue siendo elevado (57,3\% en 2015), lo cual indica un problema estructural. El Ecuador es un país capitalista subdesarrollado, con un patrón de especialización primario exportador y alta heterogeneidad estructural; es decir, siguen coexistiendo en la economía sectores productivos de alta y muy baja productividad del trabajo, con un gran peso relativo de estos últimos. El período 2007-2014 presentó un crecimiento económico redistributivo del ingreso y políticas públicas que han contribuido a disminuir el empleo informal. Sin embargo, no se ha producido un cambio relevante de la estructura productiva (Ponce y Vos, 2012, p. 24; León, 2015; Ordoñez, Samman, Mariotti y Borja, 2015, pp. 38, 39).

En los próximos años Ecuador tiene el desafío de disminuir el empleo informal en el sector informal, lo que dependerá básicamente de tres aspectos según oIT: crecimiento económico con cambio estructural que amplíe el sector formal y que reasigne trabajadores desde el sector informal hacia el sector formal y desde sectores de baja productividad a sectores de alta productividad; reforma a la seguridad social contributiva que amplíe la cobertura de los trabajadores independientes; ${ }^{32}$ y políticas que incrementen la productividad laboral de las micro, pequeñas y medianas empresas de manera que puedan sufragar los mayores costos laborales que impone el cumplimiento del pago de salarios mínimos y la afiliación a la seguridad social de sus trabajadores (oIT, 2014, p. 11). A estos se pueden añadir tres aspectos más. Primero, la coexistencia dinámicamente ineficiente del aseguramiento contributivo obligatorio de salud en el IEss y el sistema nacional de salud gratuita del Ministerio de Salud Pública. Para el largo plazo, el Ecuador debe optar por uno de los dos sistemas. Segundo, en el mediano plazo se requiere resolver la sostenibilidad del financiamiento integral de la seguridad social, lo cual demandará posiblemente reformas paramétricas y subsidios estatales. Tercero, se requiere pensar en un sistema integrado de protección social que articule y coordine el subsistema de seguridad social contributiva con el subsistema de asistencia social no contributiva.

Buena parte del período de dolarización oficial de la economía ecuatoriana coincidió con el boom de precios del petróleo y una depreciación del dólar a nivel internacional. Estas tendencias, junto con los cambios en los contratos con las empresas petroleras, otorgaron al gobierno de Rafael Correa espacio fiscal para impulsar la economía a través del gasto público y eludir las restricciones que impone la dolarización sobre el mercado laboral. Sin embargo, estas variables se han revertido desde el segundo semestre de 2014 conduciendo al país a un estancamiento económico en 2015 y probablemente también de 2016. En este nuevo contexto, el país enfrentará las limitaciones que impone la pérdida de soberanía monetaria dirigiendo los ajustes al sector fiscal y al mercado laboral. En efecto, el gobierno ha recortado el gasto público, eliminado el subsidio del $40 \%$ a la masa pensional del IEss e impulsado el proyecto de ley de optimización de la jornada laboral y del seguro de desempleo que, entre otros objetivos, busca flexibilizar el mercado laboral, lo que contrasta con la tendencia progresista de buena parte de las reformas previas.

Un aspecto positivo de esta propuesta de Ley para el propósito de reducir el empleo informal es que también eliminaría la voluntariedad de afiliación al IEss de los trabajadores autónomos, profesionales en libre ejercicio y patronos, lo que implicaría que deban afiliarse obligatoriamente. Antes, el gobierno tuvo un intento fallido en esta dirección por la oposición de los grupos de interés. En efecto, el Consejo Directivo del IEss en febrero de 2014 expidió la 
Resolución cd 464 que disponía la afiliación obligatoria de los trabajadores independientes y en marzo de ese mismo año la derogó mediante Resolución CD 467 (Proyecto suprime voluntariedad en afiliación para los no dependientes, 2016). La obligatoriedad de la afiliación es un paso para extender la seguridad social y reducir el empleo informal entre los trabajadores independientes. No obstante, este es un grupo muy heterogéneo que va desde un vendedor ambulante hasta un profesional en libre ejercicio, por lo que se requiere un esquema diferenciado de aportaciones con subsidios estatales para los trabajadores de menores ingresos.

Para terminar, es necesario señalar las limitaciones de este estudio. La primera es que se enfocó únicamente en las políticas laborales y de seguridad social que posiblemente incidieron en la reducción del empleo informal; en consecuencia, no es un análisis comprehensivo de la política laboral y de la protección social. La segunda es que se basó principalmente en un análisis estadístico descriptivo a partir de las Encuestas de Empleo, Desempleo y Subempleo del INEC $y$, por tanto, no identifica en términos cuantitativos el impacto o la relación causal entre las políticas públicas estudiadas y el cambio en el empleo informal. Además, se revisó la literatura empírica existente sobre empleo informal en el Ecuador para el período analizado que proviene principalmente del Banco Mundial y el Banco Interamericano de Desarrollo, lo cual muestra la falta de este tipo de estudios por parte de instituciones ecuatorianas, vacío que puede ser llenado a futuro por las universidades. No obstante, el uso de estudios empíricos de estos organismos de financiamiento multilateral no implica necesariamente la coincidencia con sus propuestas de política pública. Finalmente, se analizó la evolución de la legislación laboral y de seguridad social, informes institucionales y literatura empírica reciente, sin considerar otras fuentes de información como entrevistas a actores clave de instituciones públicas, sindicatos y movimientos sociales. Estas son tareas que futuras investigaciones sobre el empleo informal en el Ecuador pueden abordar.

\section{NOTAS}

1 Este artículo se elaboró sobre la base de un informe previo preparado para la oit en el año 2014 (León, 2014b) que fue utilizado como insumo para la publicación del documento Evolución del empleo informal en Ecuador: 2009-2012 (oit, 2014). Igualmente, se usaron como insumos varias columnas publicadas en el semanario MásQmenos de Diario El Telégrafo entre septiembre de 2013 y enero de 2014 (León, 2013a a 2013e y 2014a).

2 Diferencio el término comprender que significa en este caso interpretar las relaciones o vínculos entre las políticas públicas laborales y de seguridad social y los cambios en el empleo informal del término explicar que significa demostrar relaciones causales entre ellas.

3 En este artículo se utiliza la nueva definición oficial de sector informal del inec presentada en 2015 y la definición aún no oficial de empleo informal del inec. Ésta es una diferencia con León (2014b), que utilizó la definición de sector informal del inec del año 2007 y una estimación del empleo informal realizada por el autor. Agradezco al inec y sus técnicos que me proporcionaron las tablas estadísticas respectivas para este estudio.

4 Según Banco Mundial (2014, p. 37), la informalidad en el Ecuador es alta independientemente de la definición que se use y es relativamente alta en comparación con otros países de la región.

5 El Instituto Nacional de Estadística y Censos, inec, modificó las definiciones de sector informal, desempleo y subempleo desde el año 2007, por lo que estos indicadores no son comparables con los de encuestas anteriores. El inec no presenta estadísticas oficiales de empleo informal. 
6 Se debe tener la precaución de que una correlación entre dos variables igual a cero no implica necesariamente que estas sean independientes. La correlación mide únicamente el grado de asociación lineal.

7 El efecto neto del ciclo económico sobre la informalidad depende de los flujos de transición laboral que predominen. Goñi (2013, pp. 154-156) analiza la correlación entre los flujos de transición laboral y el ciclo económico en el Ecuador. Estudia el paso del desempleo al empleo, del empleo al desempleo y entre tipos de empleo (asalariado formal, asalariado informal y autoempleado). Encuentra que el paso de desempleo a asalariado formal y a autoempleo es procíclico, mientras que el paso de desempleo a asalariado informal es contracíclico. Asimismo, el paso de cualquiera de las tres categorías de empleo a desempleo es contracíclico. Finalmente, es procíclico el paso de asalariados informales a asalariados formales, de asalariados formales a asalariados informales y autoempleo a asalariados formales, mientras que es contracíclico el paso de asalariados formales a autoempleados. Obtiene que la reducción de la informalidad entre el primer trimestre de 2007 y el cuatro trimestre de 2010 se debió a un efecto balanceado entre menores entradas relativas a la informalidad (53\%) y mayores salidas relativas de la informalidad (47\%). Asimismo, el proceso de formalización entre los trabajadores asalariados está conducido por un incremento en las entradas relativas desde la informalidad y una contracción en las salidas relativas hacia la informalidad.

8 La tercerización quedó restringida únicamente a actividades que no son parte del negocio principal de la empresa tales como servicios de seguridad y limpieza.

9 Mediante Decreto Ejecutivo N. ${ }^{\circ}$ 1121, de 3 de junio de 2008, se expidió el Reglamento para la aplicación del Mandato Constituyente N. ${ }^{\circ} 8$.

10 La Disposición Transitoria segunda estableció que: Los trabajadores que se encontraban laborando bajo la modalidad de contrato por horas por más de 180 días con anterioridad a la aprobación de este mandato serán contratados de manera obligatoria bajo las distintas modalidades previstas en el Código del Trabajo según lo establecido en el artículo 2 del presente mandato. La Disposición Final Primera derogó los artículos relativos a la contratación por horas de la Ley para la Transformación Económica del Ecuador, publicada en el ro N. ${ }^{\circ} 34$ de 13 de marzo de 2000.

11 Artículo 327. La relación laboral entre personas trabajadoras y empleadoras será bilateral y directa. Se prohíbe toda forma de precarización, como la intermediación laboral y la tercerización en las actividades propias y habituales de la empresa o persona empleadora, la contratación laboral por horas, o cualquiera otra que afecte los derechos de las personas trabajadoras en forma individual o colectiva. El incumplimiento de obligaciones, el fraude, la simulación, y el enriquecimiento injusto en materia laboral se penalizarán y sancionarán de acuerdo con la ley.

12 Política 1.2. Impulsar la protección social integral y seguridad social solidaria de la población con calidad y eficiencia a lo largo de la vida con principios de igualdad, justicia, dignidad, interculturalidad, literal b. Ampliar progresivamente la cobertura de la seguridad social con especial atención para adultos mayores, mujeres, personas con discapacidades y personas que realizan trabajos no remunerados; c. Ampliar progresivamente la cobertura del seguro social campesino, extenderla hacia sectores de pesca artesanal y crear una modalidad específica de afiliación para trabajadores y trabajadoras autónomas; $\mathrm{d}$. Priorizar la asignación de recursos públicos para el incremento progresivo de la cobertura de la seguridad social para las personas que realizan trabajo doméstico no remunerado y tareas de cuidado humano. Política 6.1. Valorar todas las formas de trabajo, generar condiciones dignas para el trabajo y velar por el cumplimiento de los derechos laborales, literal e. Proveer prestaciones de seguridad social eficientes, transparentes, oportunas y de calidad para todas las personas trabajadoras, cualquiera sean las formas de trabajo que desempeñen.

13 El Instituto Ecuatoriano de Seguridad Social es una entidad pública con autonomía administrativa y financiera que se encarga de administrar el financiamiento y las prestaciones de la seguridad social en el Ecuador (seguro de invalidez, vejez y muerte, seguro de salud, seguro de cesantía y seguro de riesgos del trabajo). 14 Así, el Ministerio de Transporte y Obras Públicas, incorpora en los contratos de obra la siguiente cláusula: Requisito previo al pago de planillas: Previamente al pago de las planillas el contratista presentará el certificado de no adeudar al Instituto Ecuatoriano de Seguridad Social los aportes y fondos 
de reserva de los trabajadores que estuviese empleando en la obra y una copia de las planillas de pago al IESs. Sin este requisito el ministerio no realizará pago alguno, conforme a los arts. 86 y 87 de la Ley de Seguridad Social, publicada en el Suplemento del Registro Oficial N. ${ }^{\circ} 465$, de 30 de noviembre de 2001, excepto en el caso de que sus trabajadores estén bajo otro régimen de contratación laboral.

15 El Código de la Producción contiene una serie de incentivos que buscan estimular la inversión privada orientada a la transformación de la matriz productiva del país. Entre los principales incentivos se encuentran reducciones del impuesto a la renta, zonas especiales de desarrollo económico y contratos de inversión que otorgan estabilidad jurídica.

16 El literal d. del artículo 59 del Código de la Producción, Objetivos de la democratización, del Código de la Producción establece: Fomentar el cumplimiento de las éticas empresariales que promueve el Gobierno Nacional, a través de la creación de un sello de gestión de reconocimiento público, que permita alentar e incentivar a las empresas que realizan sus actividades respetando el medio ambiente; cumpliendo con sus empleados y trabajadores en sus obligaciones laborales y de seguridad social; y, con la comunidad, con el pago oportuno de sus obligaciones tributarias, conforme a la legislación aplicable. 17 Artículo 78. sanción penal.- Sin perjuicio del plazo de quince (15) días para la remisión de aportes, descuentos y multas al IEss, el funcionario público o el empresario privado que hubiere retenido los aportes patronales y/o personales y haya efectuado los descuentos por rehabilitación de tiempos de servicio o de dividendos de préstamos hipotecarios y quirografarios de sus trabajadores y no los deposite en el IEss dentro del plazo máximo de noventa (90) días, contados a partir de la fecha de la respectiva retención, será sancionado con la pena de tres a cinco (5) años de prisión y una multa igual al duplo de los valores no depositados.

18 Artículo 242. Retención ilegal de aportación a la seguridad social: La persona que retenga los aportes patronales o personales o efectúe los descuentos por rehabilitación de tiempos de servicio o de dividendos de préstamos hipotecarios y quirografarios de sus trabajadores y no los deposite en el Instituto Ecuatoriano de Seguridad Social dentro del plazo máximo de noventa días, contados a partir de la fecha de la respectiva retención, será sancionada con pena privativa de libertad de uno a tres años. Para el efecto, la o el afectado, el Director General o el Director Provincial del Instituto Ecuatoriano de Seguridad Social, en su caso, se dirigirá a la Fiscalía para que inicie la investigación respectiva. Si se determina responsabilidad penal de la persona jurídica, será sancionada con la clausura de sus locales o establecimientos, hasta que cancele los valores adeudados.

19 Artículo 243. Falta de afiliación al Instituto Ecuatoriano de Seguridad Social por parte de una persona jurídica: En el caso de personas jurídicas que no cumplan con la obligación de afiliar a uno o más de sus trabajadores al Instituto Ecuatoriano de Seguridad Social, se impondrá la intervención de la entidad de control competente por el tiempo necesario para precautelar los derechos de las y los trabajadores y serán sancionadas con multa de tres a cinco salarios básicos unificados del trabajador en general, por cada empleado no afiliado, siempre que estas no abonen el valor respectivo dentro del término de cuarenta y ocho horas después de haber sido notificado.

20 Artículo 244. Falta de afiliación al Instituto Ecuatoriano de Seguridad Social: La o el empleador que no afilie a sus trabajadores al seguro social obligatorio dentro de treinta días, contados a partir del primer día de labores, será sancionado con pena privativa de libertad de tres a siete días. Las penas previstas se impondrán siempre que la persona no abone el valor respectivo, dentro del término de cuarenta y ocho horas después de haber sido notificada.

21 El Consejo Directivo del IEss, mediante Resolución cd 346, de 18 de febrero de 2011, creó la Subdirección de Afiliación y Cobertura, con la competencia de diseñar y proponer programas, estrategias, acciones e instrumentos para la ampliación de la cobertura y la afiliación, el mejoramiento de la recaudación de aportes y contribuciones, y el control de la afiliación y recaudación patronal.

22 El estudio también indagó sobre las inspecciones del municipio, cuerpo de bomberos, el Servicio de Rentas Internas (SRI), autoridades sanitarias y autoridades medioambientales. Encontró que dos tercios de las empresas afirmaron haber tenido una inspección en el último año y que las de mayor incidencia fueron las realizadas por el municipio $(47,6 \%)$ y el cuerpo de bomberos (34\%). 
23 Los salarios mínimos de las empleadas domésticas, operarios de artesanía y colaboradores de la microempresa se equipararon con el de los trabajadores privados en general desde enero de 2010, mediante Acuerdo Ministerial 77, publicado en Registro Oficial 105 de 11 de enero de 2010. En 2007 el salario mínimo de las empleadas domésticas fue de usd 120 mensuales; en 2008, usd 170; en 2009, usd 200. Para los trabajadores en general, el salario mínimo fue, respectivamente, usd 170; usd 200; usd 218. Desde 2010, el salario mínimo de las empleadas domésticas es el mismo que el de los trabajadores en general, usd 240, usd 264 en 2011, usd 292 en 2012, usd 318 en 2013, usd 340 en 2014 y usd 354 en 2015.

24 Artículo 6. Añádase el siguiente artículo innumerado después del Artículo 268 del Código del Trabajo: Art. ... .- A los empleados y trabajadores domésticos se garantiza los mismos beneficios de cualquier otro trabajador en general, debiendo sus jornadas de trabajo y descanso ser de cinco días a la semana o sea cuarenta horas hebdomadarias y los días sábados y domingos serán de descanso.

25 La Asamblea Nacional mediante la Ley Reformatoria a la Ley de Seguridad Social, publicada en el Suplemento al Registro Oficial N. ${ }^{\circ} 323$ de 18 de noviembre de 2010, reformó los artículos 102, 105 y 117, ampliando la edad de los hijos de los afiliados a ser cubiertos por el seguro de salud de 6 a 18 años. Previamente, el Consejo Directivo del IEss, mediante Resolución N. ${ }^{\circ}$ cd 265, de 8 de junio de 2009, dispuso que los hijos de los afiliados sean beneficiarios hasta que cumplan los seis años de edad de acciones integrales de fomento y promoción de la salud, prevención, diagnóstico y tratamiento de enfermedades, recuperación y rehabilitación de la salud individual, cobertura que no se había realizado a pesar de constar en la Ley de Seguridad Social vigente desde 2001. Asimismo, en septiembre de 2008, el Consejo Directivo había dispuesto el inicio de atención médica a los hijos menores de los afiliados, hasta los seis años de edad, en todas las unidades médicas del IEss a nivel nacional, sin incluir provisionalmente el uso de medios de laboratorio clínico o de diagnóstico por radiología e imagen, ni tratamiento farmacológico.

26 La disposición general tercera de la Ley Reformatoria a la Ley de Seguridad Social indicada arriba estableció que: Los afiliados aportantes podrán gozar del beneficio de atención médica, desde el primer día de su afiliación, en caso de accidente o emergencia; y luego del tercer mes de aportaciones gozarán de los beneficios que el sistema brinda en salud.

27 El IEss tiene también sus propios centros de salud y hospitales mediante los cuales presta atención de salud directamente a los afiliados. Según el informe de rendición de cuentas del seguro de salud del IESS, del año 2012, entre 2010 y 2012 se acreditaron 417 prestadores externos. En el año 2012, el valor aprobado por el seguro de salud para pago a los prestadores externos fue de usd 479 millones, mientras que para los prestadores internos del IESs fue de usd 657 millones (IESS, 2012).

28 El Banco del Instituto Ecuatoriano de Seguridad Social (BIEss), que es un banco público, fue creado en el año 2009 mediante ley publicada en el Suplemento al Registro Oficial N. ${ }^{\circ}$ 587, de 11 de mayo de 2009. Realiza inversiones con los excedentes de los fondos de pensiones, salud, riesgos del trabajo y cesantía. A finales de 2015 tenía un capital total de usd 16500 millones, de los cuales un 45\% estaban invertidos en bonos del Estado y un $47 \%$ en créditos a los afiliados. Empezó a operar con los afiliados al IESS en octubre de 2010 otorgando créditos hipotecarios, quirografarios y prendarios. La cartera de crédito total del IEss a finales de 2015 ascendió a usd 7800 millones, que equivalieron al 7,8\% del PIB. Actualmente, el IEss es el principal actor en el mercado hipotecario, habiendo desplazado a la banca privada. Representa el $68 \%$ del volumen de crédito total en este segmento. Entrega créditos hipotecarios a largo plazo y con menores tasas de interés que los bancos privados.

29 Disposición transitoria segunda. Por esta sola vez los empleadores que no hubieren afiliado a sus trabajadores con relación de dependencia en los últimos tres (3) años, así no se mantenga la relación laboral en la actualidad, no serán sujetos de sanción y podrán afiliarlos extemporáneamente al IEss, dentro del plazo de seis (6) meses contados desde la expedición de esta Ley, pagando los valores correspondientes de aportación patronal y del trabajador, más el interés equivalente al máximo convencional permitido por el Banco Central del Ecuador, a la fecha de liquidación de la mora, sin recargos por multas, incrementos adicionales o de cualquier naturaleza, sin prejuicio de la responsabilidad patronal que se generare. Para los cálculos se exceptuarán los porcentajes correspondientes a los seguros de salud y riegos del trabajo. 
30 Aquí se ha enfatizado el aumento de cobertura del seguro de salud como incentivo para la afiliación a la seguridad social. Sin embargo, la sostenibilidad futura de estas reformas dependerá del adecuado financiamiento del fondo de salud, lo cual requerirá de incrementos en las cotizaciones. Tampoco se ha abordado la tensión e ineficiencia que existe entre el aumento de la cobertura del aseguramiento de salud a través del IEss, por un lado, y el incremento de la cobertura de salud mediante el Ministerio de Salud Pública, por otro.

31 La política gubernamental respecto al incremento anual de pensiones ha sido errática. Inicialmente era el Consejo Directivo del IEss el que establecía el aumento anual de pensiones sobre la base de informes actuariales. En marzo de 2009 se emitió la Ley Reformatoria a la Ley de Seguridad Social, a la Ley de Seguridad Social de las Fuerzas Armadas y a la Ley de Seguridad Social de la Policía Nacional, que estableció la regla fija de que las pensiones se incrementarán al inicio de cada año en la misma proporción que la inflación del año anterior. Luego, en octubre de 2010, se expidió la Ley Reformatoria a la Ley de Seguridad Social, que estableció que las pensiones se incrementarán anualmente a partir del mes de enero de cada año en base a un coeficiente de crecimiento que iba de 5,61\% a 16,16\% para pensiones menores o iguales a 2,5 salarios básicos unificados (SBU) y que era de 4,31\% para pensiones mayores a 2,5 SBU. Por último, en abril de 2015 se expidió la Ley Orgánica para la Justicia Laboral y el Reconocimiento del Trabajo en el Hogar que determinó que las pensiones se incrementarán al inicio de cada año de acuerdo a la inflación promedio anual del año anterior.

32 El Ministerio de Coordinación de Desarrollo Social ha trabajado un proyecto de nueva Ley de Seguridad Social que reforme integralmente el sistema; sin embargo, no ha sido enviada a la Asamblea y se ha optado por múltiples reformas parciales.

\section{REFERENCIAS}

Audiencia por ley laboral se cumplió. (2 de marzo de 2016). El Universo. Recuperado de http://www.eluniverso. com/noticias/2016/03/o2/nota/5438661/audiencia-ley-laboral-se-cumplio

Asamblea Constituyente (2008). Mandato Constituyente N. ${ }^{\circ}$ 8. Montecristi, Ecuador.

Banco Mundial (2012). Ecuador, Las caras de la informalidad. Informe N. ${ }^{\circ} 67808$-EC. Recuperado de http://www-wds.worldbank.org/external/default/wDSContentServer/wDSP/ıв/2013/04/o1/ooo 442464_20130401121008/Rendered/PDF/678080spanishooBoxo374379BoopubLICo.pdf

Banco Mundial (2014). Ecuador. Informalidad y mercado laboral. Informe N. ${ }^{\circ}$ 90486-EC. Quito.

Bosch, M., Melguizo A. y Pagés C. (2013). Mejores pensiones mejores trabajos. Hacia la cobertura universal en América Latina y el Caribe. BID.

Goñi, E. (2013). Andemic Informality. Assesing Labor Informality, Employment, and Income Risk in the Andes. IADB.

INEC (2007-2015). Encuestas de empleo, subempleo y desempleo.

León, M. (16 de septiembre de 2013a). Sector y empleo informales en el Ecuador. Semanario MásQmenos de Diario El Telégrafo. Recuperado de http://www.telegrafo.com.ec/economia/masqmenos/item/ sector-y-empleo-informales-en-ecuador.html

León, M. (o2 de diciembre de 2013b). Crecimiento económico, política pública e informalidad. Semanario MásQmenos de Diario El Telégrafo. Recuperado de http://www.telegrafo.com.ec/economia/masqmenos/item/ crecimiento-economico-politica-publica-e-informalidad.html

León, M. (o9 de diciembre de 2013c). Evolución del empleo doméstico remunerado en el Ecuador, Semanario MásQmenos de Diario El Telégrafo. Recuperado de http://www.telegrafo.com.ec/ economia/masqmenos/item/ evolucion-del-empleo-domestico-remunerado-en-el-ecuador.html 
León, M. (16 de diciembre de 2013d). Penalización de la no afiliación al IEss y empleo informal. Semanario MásQmenos de Diario El Telégrafo. Recuperado de http://www.telegrafo.com.ec/economia/masqmenos/item/pe nalizacion-de-la-no-afiliacion-al-iess-y-empleo-informal.html

León, M. (23 de diciembre de 2013e). La afiliación a la seguridad social se volvió más atractiva. Semanario MásQmenos de Diario El Telégrafo. Recuperado de http://www.telegrafo.com.ec/economia/masqmenos/item/la-afiliacion-a-la-seguridad-social-se-volvio-mas-atractiva.html

León, M. (6 de enero de 2014a). Los límites de las políticas para reducir el empleo informal. Semanario MásQmenos de Diario El Telégrafo. Recuperado de http://www.telegrafo.com.ec/economia/masqmenos/item/los-limites-de-las-politicas-para-reducir-el-empleo-informal.html

León, M. (2014b). Políticas públicas para la reducción del empleo informal. Documento preparado para la OIT.

León, M. (2015). Ecuador, 1990-2013: Crecimiento, productividad y cambio estructural. Ponencia presentada en el III Congreso Latinoamericano y Caribeño de Ciencias Sociales. FLAcso-Ecuador. 26 al 28 de agosto.

INEC (2007-2015). Encuesta nacional de empleo, desempleo y subempleo. Quito: INEC.

IESS (2011). Informe de rendición de cuentas. Recuperado de http://www.iess.gob.ec/documents/10162/ 83914/DIRECCION+GENERAL.pdf

Ministerio Coordinador de Desarrollo Social (2010). Agenda Social 2009-2011. Quito, Ecuador.

Ministerio Coordinador de Desarrollo Social (2012). Agenda Social 2012-2013. Quito, Ecuador.

Ministerio Coordinador de la Producción, Empleo y Competitividad (2010). Agenda para la transformación productiva. Quito, Ecuador.

Ministerio de Relaciones Laborales (2010). Informe de rendición de cuentas 2010. Recuperado de http://www. relacioneslaborales.gob.ec/wp-content/uploads/downloads/2012/o8/Consejo-departicipaci\% $\mathrm{C}_{3} \% \mathrm{~B}_{3}$-Ciudadana-2010-CPCCs.pdf

Ministerio de Relaciones Laborales (2011). Informe de rendición de cuentas 2011. Recuperado de http:// www. relacioneslaborales.gob.ec/wp-content/uploads/downloads/2012/o8/Secretaría-deTransparencia-de-Gestión-defensoria-del-pueblo.pdf

Ministerio de Relaciones Laborales (2012). Informe de rendición de cuentas 2012. Recuperado de http:// www.produccion.gob.ec/wp-content/uploads/downloads/2013/o2/Informe-Rend-Ctas-MRL.pdf

Ministerio de Relaciones Laborales (2013). Plan Estratégico Institucional 2013, Recuperado de http://www. relacioneslaborales.gob.ec/wp-content/uploads/downloads/2013/11/Plan-Estratégico-AnualOctubre-2013.pdf

OIT (1993). Resolución sobre las estadísticas del empleo en el sector informal, adoptada por la decimoquinta Conferencia Internacional de Estadísticos del Trabajo. Recuperado de http://www.ilo.org/ wcmsp5/groups/public/---dgreports/---stat/documents/normativeinstrument/wcms_087486.pdf OIT (2003). Informe General. Decimoséptima Conferencia Internacional de Estadísticos del Trabajo. Ginebra. Recuperado de http://www.ilo.org/wcmsp5/groups/public/---dgreports/---stat/documents/meetingdocument/wcms_o87587.pdf

OIT (2014). Evolución del empleo informal en Ecuador: 2009-2012. Notas sobre formalización. FORLAC. Recuperado de http://www.ilo.org/wcmsps/groups/public/---americas/---ro-lima/documents/ publication/wcms_ 245616.pdf

Ordoñez, A., Samman E., Mariotti C., Borja, I. (2015). Sharing the Fruits of Progress. Poverty Reduction in Ecuador. Case Study Report Material Wellbeing. ODI. London. 
Ponce, J. y Vos, R. (2012). Redistribution without Structural Change in Ecuador. Rising and Falling Income Inequality in the 1990 os and 200os. Working Paper, (12), UNU-WIDER.

Primera demanda contra la Ley de Justicia Laboral. (23 de abril de 2015). El Tiempo. Recuperado de http:// www.eltiempo.com.ec/noticias-cuenca/160853-primera-demanda-contra-la-ley-de-justicia-laboral/

Proyecto suprime voluntariedad en afiliación para los no dependientes. (29 de febrero de 2016). El Universo. Recuperado de http://www.eluniverso.com/noticias/2016/o2/29/nota/5435676/ proyecto-suprime-voluntariedad-afiliacion-no-dependientes

SENPlades (2009). Plan Nacional para el Buen Vivir: Construyendo un Estado Plurinacional e Intercultural. Quito, Ecuador.

SENPLAdes (2013). Plan Nacional de Desarrollo/Plan Nacional para el Buen Vivir 2013-2017. Quito, Ecuador. Sexta demanda contra la Ley de Justicia Laboral en la Corte Constitucional. (20 de mayo de 2015). El Mercurio. Recuperado de http://www.elmercurio.com.ec/480o85-sexta-demanda-contra-la-leyde-justicia-laboral-en-la-corte -constitucional/\#.VtdqpObRaus 
